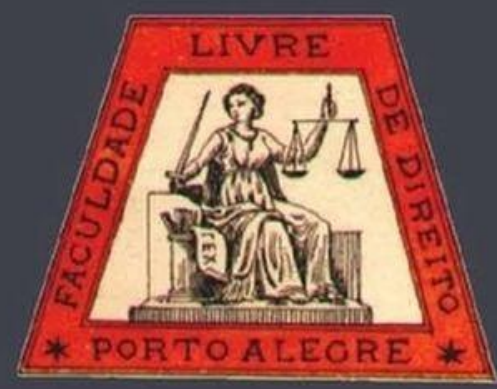

Transplantes Jurídicos: história, teoria e crítica no Direito Comparado

Legal transplants: history, theory and critical approach in Comparative Law

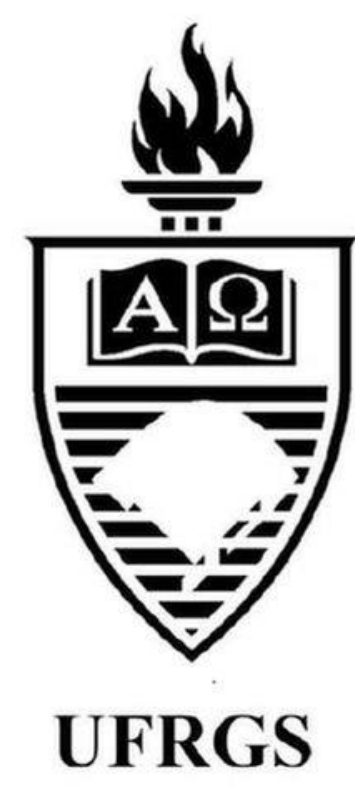

Deo Campos Dutra

Faculdade de Direito Doctum de Juiz de Fora 


\title{
Transplantes Jurídicos: história, teoria e crítica no Direito Comparado
}

\author{
Legal transplants: history, theory and critical approach in Comparative Law
}

\section{REFERÊNCIA}

Deo Campos Dutra*

DUTRA, Deo Campos. Transplantes Jurídicos: história, teoria e crítica no Direito Comparado. Revista da Faculdade de Direito da UFRGS, Porto Alegre, n. 39, p. 76-96, dez. 2018.

\begin{abstract}
RESUMO
O objeto principal desta investigação é a análise dos transplantes jurídicos no âmbito da teoria do direito comparado. Para isso, ele se propõe a dividir-se em dois momentos principais. Num primeiro recorte planejamos oferecer ao leitor uma compreensiva abordagem sobre as principais perspectivas que interpelam o tema, sua história, características e conflitos. Numa segunda fase oferecemos a construção de uma abordagem que congrega duas perspectivas críticas do estudo dos transplantes jurídicos. Esta abordagem ambiciona oferecer ao leitor uma alternativa analítica e crítica para a condução dos estudos jurídicos que pretendem analisar a transferência de itens jurídicos de um ordenamento jurídico a outro.
\end{abstract}

\section{PALAVRAS-CHAVE}

Transplantes jurídicos. Teoria da Comparação Jurídica. Direito Comparado.

\section{ABSTRACT}

The main object of this investigation is the analysis of legal transplants within the scope of comparative law theory. For this, it divides into two main moments. At first, we plan to offer the reader a comprehensive approach on the main perspectives that address the theme, its history, characteristics and conflicts. In a second phase, we offer the construction of an approach that brings together two critical perspectives of the study of legal transplants. This approach aims to offer the reader an analytical and critical alternative to conducting legal studies that seek to analyse the transfer of legal items from one legal system to another.

\section{KEYWORDS}

Legal Transplants. Theory of Legal Comparison. Comparative law.

\section{SUMÁRIO}

Introdução. 1. O que são os transplantes jurídicos? História, conceito e conflitos. 2. Como, afinal, compreender os Transplantes Jurídicos? Teoria e crítica. Referências.

\section{INTRODUÇÃO}

É frequente nas graduações das faculdades de Direito em todo o Brasil ouvirmos dos professores que parte de nosso ordenamento jurídico, notadamente nossos códigos, são resultados de um trabalho que envolve, entre outros, processos de assimilações ou inspirações de sobretudo grandes codificações estrangeiras.

Essas primeiras informações, por sua vez, não passam de uma pontual referência introdutória para os estudos dogmáticos de diversas áreas do nosso Direito. Perguntas que desafiam a origem desses expedientes, suas razões e procedimentos quase nunca são feitas em sala de aula.

As fundamentais características desses códigos, de seus sistemas legais, sua contextualização e contradições, por sua vez, raramente são objeto de uma detida reflexão, apesar de terem em seu âmago questões que são fundamentais para a compreensão destes influentes instrumentos. Tampouco sua "transferência" para o Brasil é questionada,

\footnotetext{
* Professor e coordenador de pesquisa da Faculdade Doctum em Juiz de Fora/MG. Doutor em Direito pela PUC/RJ e pela Universidade Paris X, mestre em Direito Comparado pela Universidade de Paris 1 - Panthéon Sorbonne. Foi pesquisador visitante na EHESS/Paris e pesquisador visitante na Queens Univesity/Canadá. Realizou seu estágio pós-doutoral em Direito Comparado na École Normale Supérieure de Paris.
} 
indagando, por exemplo, como teve origem o procedimento de "empréstimo" de uma lei ou código estrangeiro, ou como até que ponto ele influenciou a formulação da legislação pátria.

Desconfiamos que a ausência dessas perguntas, e a consequente exiguidade na dedicação de uma considerável parte do tempo em trabalhar sua compreensão com os estudantes, é resultado direto de um problema estrutural na produção e difusão do conhecimento do direito no Brasil: a pouca atenção dada ao estudo do direito comparado.

Ao abordarmos esse processo de influência, ou transferência, de normas ou até mesmo de doutrinas estrangeiras, entramos diretamente no campo daquilo que ficou conhecido no âmbito da teoria do direito comparado como o estudo dos "transplantes jurídicos".

A importância deste estudo é geralmente desprezada, abdicando do fato de que ele pode proporcionar uma série de debates fundamentais para a compreensão da origem e das influências do sistema jurídico brasileiro. Não precisamos reafirmar, aqui, a dimensão da relevância contida na compreensão das diversas interposições externas na formulação do direito em um país como o Brasil.

Com suas características históricas, sociais e culturais e seus consequentes reflexos ontológicos e epistemológicos no campo do Direito, o Brasil tem um terreno profícuo para explorar em torno do tema, especialmente na maneira com a qual a academia jurídica brasileira questiona e reflete sobre essas interferências e sua incorporação em nosso sistema jurídico. Isto porque a compreensão das origens desses itens que serviram como inspirações para nossos textos legais, sua detida contextualização e o detalhamento de seus principais institutos e razões jurídicas são fundamentais para uma melhor percepção de nosso próprio sistema jurídico.

Assim, ao identificar os limites e possibilidades de uma normativa estrangeira que influenciou nossos textos locais, podemos produzir uma melhor reflexão sobre nossa própria legislação. Isso não significa, evidentemente, que não exista na literatura jurídica brasileira bons trabalhos sobre o tema. É justamente a escassez deles que evidencia a gravidade do problema.

Este processo poderia, por exemplo, produzir estudos de impacto como o realizado pelo professor James W. Whitman (2017), que recentemente identificou que as normativas antissemitas adotadas pela Alemanha nazista tinham sua inspiração nas leis de segregação raciais norte-americanas. Eles serviriam, portanto, não só para a promoção de possíveis e instigantes debate dentro da academia brasileira, mas certamente irradiariam aos estudos dogmáticos uma boa dose de reflexão crítica do direito.

Se o estudo do processo de transferência, influência, recepção e adaptação de normativas estrangeiras dentro de nosso sistema jurídico é quase sempre restrito as páginas iniciais dos (bons) manuais, a compreensão teórica dos desdobramentos deste fenômeno estudado pelo direito comparado é ainda pouco conhecida. Assim, questões fundamentais como, por exemplo, aquelas que debatem a colonização intelectual que esses institutos podem exercer, não são sequer aventadas em diversos cursos de graduação.

Desta forma, grande parte da potencialidade do estudo dos chamados transplantes jurídicos, qual seja, uma melhor compreensão da formação do nosso próprio sistema normativo, com suas influências, contradições e colonizações, deixa de ser produzida e debatida entre nossos alunos e, consequentemente, nossos operadores.

A importância deste estudo também se nota na medida em que, ao analisarmos a possibilidade ou não da acomodação de uma pluralidade de modelos estrangeiros nos mais distintos sistemas jurídicos, nos aproximamos a debater de maneira mais crítica processos de universalização legais 
que são ponto central em trabalhos jurídicos preocupados com objetos como reforma política, crescimento econômico e progresso social (GRAZADEI, 2009, p.727).

É notória, por exemplo, a reação da comunidade acadêmica francesa aos estudos realizados pelo Banco Mundial que apontavam como uma de suas dificuldades para o crescimento econômico seu próprio sistema jurídico, oferecendo como modelo sistemas legais de países da common law. ${ }^{1}$

O mesmo pode ser dito para o Brasil que, paradoxalmente, vê a prática constante dos "transplantes jurídicos" por parte da comunidade de juristas ser proporcionalmente inversa à ampla análise e debate em torno do ato e do discurso de importação de teses, instituições e normas jurídicas provenientes do exterior. $^{2}$

Tocados por essa indagação proveniente de uma percepção intuitiva do tema, este artigo tem como objetivo principal a realização de uma introdução crítica ao estudo dos denominados transplantes jurídicos. O intuito essencial deste trabalho e abrir caminhos que possibilitem a colocação de tal tema como ponto de interesse e pesquisa dentro da comunidade acadêmica brasileira.

Uma melhor compreensão dos chamados transplantes jurídicos pode oportunizar uma série de novos desdobramentos, nos mais diversos campos do saber jurídico que, necessariamente, devem dialogar com a teoria da comparação jurídica para que sejam bem-sucedidos. Neste sentido, esta pesquisa objetiva a proporcionar uma maior e, esperamos, melhor divulgação deste

\footnotetext{
${ }^{1}$ As reações francesas ao estudo foram duras e em grande quantidade. Para todas, ver: VALCKE, Catherine. The French Response to The World Bank's Doing Business Reports. In: University of Toronto Law Journal, vol. 60, 2010. pp.197-217

${ }^{2} \mathrm{O}$ fenômeno nos parece ser primo-irmão do desprezo de muitos juristas brasileiros por estudos como, por exemplo, o da história do pensamento político-jurídico brasileiro.
}

importante campo do direito, a teoria do direito comparado.

Dentro dessas premissas, dividimos este texto em seus dois principais objetivos. $\mathrm{O}$ primeiro deles dedica-se a analisar os pontos centrais do debate em torno de um dos principais e recorrentes temas do direito comparado: os transplantes legais. $\mathrm{O}$ intuito aqui é apresentar o "estado das coisas" da discussão sem, contudo, pretender exaurir suas complexas e numerosas questões. Pretendemos, sobretudo, oferecer ao leitor um primeiro arcabouço teórico sobre o tema, seus debates e seus principais desdobramentos.

Num segundo momento, ambicionamos abordar as propostas de Günther Frankenberg e Michelle Graziadei sobre a análise e aplicação dos transplantes jurídicos. Neste sentido, nosso objeto de reflexão principal consistirá em oferecer ao leitor uma leitura cruzada das construções destes autores como uma das maneiras mais rigorosas e críticas de pesquisar a aplicação da "transferência" de itens jurídicos de um sistema estrangeiro a outro.

Ao mesmo tempo, já em nossa segunda parte, pretendemos debater sobre as consequências deste tipo de processo, especialmente no que tange a "idealização" da norma transplantada e a decorrente colonização intelectual resultada deste processo.

Este trabalho se situa, portanto, na interseção entre a teoria do direito comparado e uma sociologia das teorias do direito comparado. Para isso adotaremos em ambos os momentos deste texto um processo metodológico descritivo e analítico, privilegiando pesquisas qualitativas

Para detalhes, no campo do direito constitucional, ver: LYNCH, Christian Edward Cyril; MENDONÇA, José Vicente Santos de. Por uma história constitucional brasileira: uma crítica pontual à doutrina da efetividade. In: Direito e Práxis, vol 8, no2, 2017. pp.974-1007. O autor agradece a Sérgio Maia Tavares pelo insight e indicação bibliográfica valiosos. 
de cunho bibliográfico

DESPLATS, 2014, p. 10-14).

\section{O QUE SÃO OS TRANSPLANTES JURÍDICOS? HISTÓRIA, CONCEITO E CONFLITOS}

Em importante e referenciado estudo em homenagem a Alan Watson, John Cairns produz aquele que pode ser considerado uma das melhores "arqueologias" do estudo dos transplantes jurídicos (2013, p. 638). Num esforço de pesquisa histórica ${ }^{3}$, o autor escocês desenvolve um minucioso trabalho sobre um conceito da teoria do direito comparado que ganhou amplo espaço através da publicação do bastante debatido livro de Alan Watson, lançado em 1974, denominado Legal Tansplants. ${ }^{4}$

Uma das maiores contribuições do texto de Cairns é iluminar o estudo de autores que se utilizaram do termo antes mesmo da obra referencial de Watson. $O$ primeiro autor a empregar de forma metafórica o termo transplantes, utilizando a palavra como verbo no sentido de "transplantar leis" foi Jeremy Bentham. Em sua obra Time and Place, de 1782, o autor inglês desenvolve três capítulos inteiramente dedicados ao estudo do tema, abordando assuntos como uma teoria própria de transplantes jurídicos, com nove técnicas para que um transplante seja bem-sucedido e suas possíveis resistências (HUXLEY, 2007, p.182). ${ }^{5}$

Segundo Cairns, após Bentham, o autor que adotou a metáfora de transplantes legais mais cedo foi o inglês Frederick Walton, em 1927. Walton incorpora a ideia de transplantes legais de

\footnotetext{
${ }^{3}$ Para um exemplo sobre os importantes estudos que transitam entre a História do Direito e o Direito Comparado, ver: DUVE, Thomas. Legal traditions: A dialogue between comparative law and comparative legal history, Comparative Legal History, vol. 6, n 1, 2018, p.15-33. O autor agradece a sugestão desta referência a um dos colegas revisores deste trabalho.
}

sua experiência pessoal, notadamente no campo acadêmico ao lecionar em países que viviam sob o domínio da coroa britânica, como o Egito, ou em países fortemente influenciados pelo direito inglês, como o Canadá e a Escócia.

Aliado a seus estudos em direito romano, Walton manifesta-se abordando o tema perante a Academia Internacional de Direito Comparado um artigo intitulado "The Historical School of Jurisprudence and Transplantations of Law" (1927). Neste texto, em que analisa o pensamento de Savigny, Walton parece adiantar um dos debates mais profícuos da teoria dos transplantes jurídicos: a possibilidade ou não da interferência da cultura na transferência de normativas legais entre sociedades.

A posição de Savigny, que sustentava uma "conexão orgânica" entre a formação da lei local e o caráter do povo que a formula, questiona Walton, não levava em consideração o surgimento de uma classe de juristas profissionais que, por sua vez, atuariam no sentido de entenderem como é possível a incorporação de novas normativas que são exteriores a esta sociedade para aprimorar seu próprio sistema. Para isso, é necessário, portanto, ocorrer o deslocamento dessas normativas do sistema jurídico "doador" a fim de serem incorporadas a um sistema jurídico "receptor".

Em suma, é possível, afirma Walton, ao contrário do que propunha Savigny, identificar dentro do arcabouço jurídico de um sistema legal "construções jurídicas" que não surgiram dentro da sociedade que as adota, mas sim que foram incorporadas de outros ordenamentos estrangeiros. $\mathrm{O}$ autor descreve este fenômeno

\footnotetext{
${ }^{4}$ WATSON, Alan. Legal Transplants: An Approach To Comparative Law. 2 ed‥ Georgia: University of Georgia Press, 1993

${ }^{5}$ Para um estudo sobre o usa das metáforas advindas da biologia pelo direito, especialmente no caso dos transplantes legais, ver: GLENN, H. Patrick. On the Use of Biological Metaphors in

Law: The Case of 'Legal Transplants'. In: Journal of Comparative Law, vol.1, no2, 2006, pp. 358-364
} 
como "Transplantation of Legal System" (WALTON, 1927, p. 187).

Essa primeira construção teórica sobre o fenômeno, apesar de se aproximar da popularizada por Watson, não pode ser confundida com ela. Neste caso, há uma fundamental preocupação com o fato do empréstimo de legislação. Não há, aqui, uma atenção detida ao reconhecimento das implicações da compreensão da lei por parte dos sistemas receptores e do seu posterior desenvolvimento (CAIRNS, 2013, p.693). Por outro lado, ela nos auxilia na percepção daquilo que pode ser considerado como um primeiro conceito para a alegoria utilizada.

Segundo Graziadei (2015, p.443) o termo "transplante jurídico" é uma metáfora que pretende expressar a gradual difusão de um Direito, ou o processo de difusão de um Direito, que leva à alteração de um determinado ordenamento jurídico através da apropriação de ideias estrangeiras. De forma similar, são empregadas expressões como "circulação de modelos jurídicos" (WISE,1990); "transferência" (FRANKENBERG, 2013); "recepção “ (SACCO, 1974); "transposição" (ORUCU, 2002), ou até mesmo "influência" ou "inspiração". 6

No contexto do direito constitucional, por exemplo, Choudhry (2006, p.1- 35) propõe a metáfora da "migração de ideias" que enfatiza a sua análise no movimento das próprias construções teóricas através de diversos sistemas legais, sem necessariamente implicar num processo de controle de sua originalidade ou de incorporação ${ }^{7}$.

\footnotetext{
${ }^{6}$ Em que pese algumas ligeiras distinções, as expressões adotadas não se diferenciam de forma substancial do conceito de Graziadei exposto neste trabalho. Neste sentido, e para fins desta pesquisa, adotaremos todas como sinônimos, inclusive os termos "transplantes legais" e "transplante jurídicos". Por outro lado, e segundo Frankenberg, cada termo opera como o significado de diferentes perspectivas e projetos teóricos a respeito do tema (2013, p.04). Para uma possível tipologia dos
}

Paralelamente, outra importante contribuição ao estudo dos transplantes jurídicos foi produzida de forma contemporânea ao trabalho de Watson, pelo professor Otto Kahn Freund. $\mathrm{O}$ autor faz alusão a um transplante de órgãos em seu texto e desenvolve o argumento de transferência de ideias jurídicas como sendo de dois tipos. Os transplantes mecânicos seriam aqueles que ocorreriam de forma fácil e os orgânicos seriam, por sua vez, os mais difíceis de serem realizados (KAHN-FREUND, 1974, p.610).

Ponto importante da contribuição de KahnFreund é seu profundo desacordo com Watson sobre a facilidade da transposição de ideias jurídicas. Para Watson, o "empréstimo" de normas, instituições, em suma, de ideias jurídicas é a maneira mais comum para o desenvolvimento do Direito.

Esse empréstimo, por sua vez, não significa a compreensão plena do sistema doador por parte do sistema receptor, ou seja, do sistema que faz o transplante sobre o ordenamento jurídico de onde essas ideias foram capturadas. Neste sentido, o estudo do direito comparado deve ser compreendido como o estudo das relações entre os sistemas legais envolvidos neste processo de empréstimo.

Em sentido contrário, e se apoiando em Montesquieu, Kahn-Freund afirma que os fatores do ambiente social para o onde a norma estaria sendo transplantada seriam tão decisivos que o próprio sentido do transplante se perderia, tal seria a alteração da acepção do objeto transplantado no momento de sua incorporação e posterior aplicação.

transplantes baseada na sociologia, ver: MILLER, Jonathan M. A Typology of Legal Transplants: Using Sociology, Legal History and Argentine Examples to Explain the Transplant Process, In: The American Journal of Comparative Law. Vol. 51, 2003. Pp.839-886.

7 Para a defesa da possibilidade do transplante das "ideias" do direito, ver: GOLTZBERG, Stefan. Les sources du droit. Paris: PUF, 2016. pp.108-118. 
Para Kahn-Freund, todo estudioso ou operador do direito que pretenda fazer uso de um eventual transplante jurídico deve levar obrigatoriamente em consideração a natureza da sociedade que produziu a norma que está sendo transplantada. A despreocupação com essa necessidade pode, inclusive, comprometer todo o transplante.

Segundo o autor, sua intenção era destacar a necessidade do conhecimento não somente da legislação estrangeira, mas também de seu contexto social e político. Neste sentido, a utilização do direto comparado para fins práticos se torna abusiva quando o há a influência de um "espírito legalista que ignora o contexto da lei." (KAHN -FREUND, 1974, p.27).

Um ponto é interessante ressaltar. De uma certa maneira, podemos afirmar que o problema apontado por Montesquieu (1748, posição 151) quando analisou a recepção do Direito Romano na Europa, qual seja, a possibilidade de um eventual conflito entre as condições culturais e sociais locais e a lei importada, e a sua intrínseca conexão com a constituição da sociedade, pode ser considerada como ainda hoje o grande objeto de debate dentro do estudo dos transplantes jurídicos. $^{8}$

Watson, em resposta, constitui a ideia de que o sucesso ou não de um possível transplante jurídico não está vinculado as observações levantadas pela crítica de Freund. Para ele, o sucesso de um empréstimo legal pode ser constatado sem que necessariamente os sistemas envolvidos sejam contextualmente próximos. Isso porque o que seria importante é a ideia que está sendo analisada, que por sua vez pode ser alterada para ser incorporada. O sucesso ou o fracasso do empréstimo legal, para Watson, não tem nenhuma ligação com o conhecimento do contexto político,

\footnotetext{
${ }^{8}$ Para detalhes sobre a relação orgânica entre a sociedade e sua legislação, ver: LAUNAY, Robert. Montesquieu: The Specter of Despotism and the Origins of Comparative Law.
}

social ou econômico da lei estrangeira (WATSON, 1976, p.294).

Por este ângulo, Watson parece mais preocupado em determinar como bem-sucedido o fato efetivo do transplante, ou seja, sua realização por si mesma e não as possíveis consequências positivas ou negativas do ato (EWALD, 1995).

Para Cairns, que analisa com cuidado o desacordo entre os autores, a ênfase de Watson não estava na contextualização do sistema que estava servindo de fonte, mas sim no sistema que estava realizando o transplante. Isso não significa, completa, que o contexto político e social não possa ser um importante fator para a implementação deste transplante com os resultados pretendidos pelos envolvidos (CAINRS, 2013, p. 647).

Este debate deu origem a diferenciação feita por Eric Stein entre a "perspectiva sociológica" dos transplantes legais, através de uma visão "micro-legal" do processo de empréstimo, adotada por Kahn-Freund e a "perspectiva de historicista do direito", através da análise "macrolegal" assumida por Watson que irá influenciar diversos juristas, como veremos a seguir (STEIN, 1977, p. 199-204).

Embora possamos entender que ambos os autores falam do conjunto de conteúdos que formam um ordenamento jurídico, nenhum deles aborda de forma detida quais seriam os "objetos" possíveis de serem transplantados de um ordenamento a outro.

É somente com a contribuição de Rodolfo Sacco que o tema ganha maior clareza. Seu trabalho pode ser considerado inovador na medida em que ele pretende propor aquilo que se designou de "formatos legais" (SACCO, 1991, p. 22). ${ }^{9}$

Para o professor, existem nas ordens jurídicas diversos formatos jurídicos. Entre esses

In: RILES, Annelise (ed). Rethinking the Masters of Comparative Law. Oxford: Hart Publishing, 2001.p.22-40 
formatos podemos elencar, por exemplo, a lei, as regras prescritas pelas decisões judiciárias e as proposições sobre o direito contidas nas obras da doutrina.

Esses formatos, por sua vez, não estão necessariamente em harmonia entre eles e é uma tarefa árdua produzir o conhecimento do direito através de uma investigação que envolva todos. Para isso, é necessário levar também em consideração elementos provenientes da filosofia, da política e até mesmo da religião. Assim, devemos realizar uma avaliação que inclua o peso de cada um desses elementos nos formatos (fontes, jurisprudência ou doutrina) num dado momento histórico (HALPERIN, 2009, p. 37).

Somente com a detida e complexa análise de cada formato jurídico é que poderemos, afinal, continua Sacco, identificar quais formatos são possíveis de serem transplantados de um sistema ao outro. Nesta lógica, completa, poucos são os sistemas jurídicos que podem ser produtores de formatos exportáveis. Isso se dá, sobretudo, porque poucos sistemas possuem uma posição de força ou prestígio capazes de proporcionarem tal comportamento (SACCO, 1991a, p.384). Ao mesmo tempo, é possível identificarmos efeitos contrários aos pretendidos ao realizar os transplantes. ${ }^{10}$

Apesar das dificuldades e da complexidade da sua realização, o empréstimo e a imitação de formatos jurídicos adotados em outros sistemas estrangeiros possuem central importância para a efetivação de diversas mudanças. Juízes podem "pegar emprestado", notadamente através de imitação, -seja de outros juízes locais, como de tribunais supranacionais ou internacionais-, soluções legais estrangeiras, assim como

\footnotetext{
${ }^{10}$ Para um efeito contrário ao pretendido no transplante jurídico, ver: GRANDE, Elisabetta. Legal Transplants and the Inoculation Effect: How American Criminal Procedure Has Affected Continental Europe. In: The American Journal Of Comparative Law, vol. 64, 2016. Pp.583-618

${ }^{11}$ Para Pier Monateri, esse processo realizado pelas elites jurídicas de cada sistema é praticamente inconsciente e está
}

legisladores o fazem ao adotar modelos estrangeiros como inspiração.

Juízes também podem adotar formulações doutrinárias que foram desenvolvidas levando em consideração casos existentes em países diversos do seu, mas que nem por isso perdem a influência caso o "juiz inspirado" se sinta inclinado a concordar com a formulação teórica original ${ }^{11}$.

Para Sacco, similaridades culturais, sociais e econômicas são cruciais para fomentar um ambiente que privilegie o empréstimo de um formato desenvolvido pelo direito estrangeiro em detrimento da formulação de um novo formato local. Mas elas não são, como já afirmamos, as únicas razões. Duas causas podem ser identificadas como principais justificativa para o "empréstimo" dos formatos legais.

A primeira delas é a imposição. Em que pese atualmente serem mais raras, a empreitada colonial realizada principalmente pelos países europeus foi a causa de uma série de transplantes legais no decorrer da história. Por outro lado, atualmente é o desejo de apropriar-se de formatos considerados "bem-sucedidos" que levam sistemas jurídicos a adotarem formulações estrangeiras.

Isto porque estes formatos possuem aquilo que o autor denomina de prestígio. Mesmo que essa formulação tautológica denominado prestígio não tenha sido investigada pelo direito comparado, ela pode ser observada em diversos comportamentos em numerosos países. (SACCO, 1991, p.399).

No mesmo sentido, Graziadei identifica três importantes fatores de alteração legal que devem ser levados em conta pelo estudioso dos transplantes legais. Dois deles coincidem com

atrelado ao vínculo ideológico que cada um dos atores dessa elite possui. Ele as denomina de contaminação. Para detalhes, ver: MONATERI, Pier Giuseppe. The 'Weak Law': Contaminations and Legal Cultures. In: Global Jurist Advances, Vol.1, no 3, 2001. pp.2-23 
aqueles elencados por Sacco: a imposição e a influência (denominada por Sacco como prestígio). O terceiro, por sua vez, está conectado a ideia de performance econômica e o transplante de instituições jurídicas.

Para Graziadei, os transplantes jurídicos foram durante muitos anos resultado direto de conquistas militares ou expansões. A extensão da lei alemã à Áustria no século vinte, a "sovietização" do direito na Europa Central e do Leste após a Segunda Guerra e o colonialismo europeu, são exemplos que nos ajudam a compreender como a transposição de normativas jurídicas podem, em determinados momentos, serem dramáticas e, exatamente por isso, resultarem numa ampla rejeição da comunidade imposta a elas.

Por outro lado, e aqui reside um objeto de trabalho interessante, a imposição de novas leis por regimes dominantes às sociedades dominadas faz surgir uma noção contraditória de legalidade. Isso acontece, por exemplo, quando certas leis adotam a estratégia de diferenciação entre os habitantes de certas colônias (GRAZIADEI, 2015, p.457).

Se historicamente o processo de transferência de ideias legais é resultado do uso da força, hoje ele se dá fundamentalmente através do trabalho dos profissionais do direito, em especial da academia. O prestígio também pode ser considerado um fato minimamente reconhecido como justificativa para a adoção de formatos legais por parte de diversos ordenamentos.

Em geral, a mudança legal influenciada pelo prestígio envolve uma série de elementos. Fatores como resultados "bem-sucedidos" em seus sistemas de origem ou até mesmo uma identificação por parte daqueles que reproduzem o elemento transplantado com seus autores originais podem justificar a escolha pela adoção de um transplante jurídico (GRAZIADEI, 2015, p. 458).
$\mathrm{O}$ respeito pela comunidade acadêmica alemã, por exemplo, influência de maneira determinante uma série de acadêmicos e práticos brasileiros, assim como o faz com seus congêneres norte-americanos (REIMANN, 1993, p.115).

O terceiro importante fator que deve ser levado em conta pelo estudioso dos transplantes jurídicos é a importante preponderância que os programas de reforma legal visando uma "melhor performance econômica" (GRAZIADEI, 2015, p. 458). Sob a égide deste argumento, diversos projetos de uniformização jurídica foram apresentados, por exemplo, pelo Banco Mundial e a Organização Mundial do Comércio com o intuito de, no fundo, realizarem transplantes jurídicos que pudessem promover os interesses de agentes econômicos.

Neste sentido, torna-se importante para o estudioso do direito comparado atentar-se para os aspectos extrajurídicos envolvidos no processo de transplante que, em tese, pretende facilitar o método de eficiência econômica das instituições legais, mas que, sobretudo, acoberta importantes e fundamentais papéis contra ou favor dessas alterações.

Sem a atenção a aspectos importantes deste fator de transplante, como o político e social os estudos dos transplantes legais que abordam a eficiência econômica devem ser considerados estudos imprecisos, muitas vezes, submetidos ao complexo, histórico e influente fenômeno político/econômico que, ao fim e ao cabo, instrumentaliza o direito.

O conceito de formatos legais e seus "empréstimos", desenvolvido por Sacco, foi objeto de amplo debate dentro dos círculos comparatistas e, segundo Halpérin, parece ter sido a maneira que o autor italiano utilizou para contrapor-se ao culturalismo (2009, p.37), uma das mais instigantes críticas ao conceito de transplante legais, como veremos posteriormente. 
Outra importante crítica à metáfora dos transplantes teve origem na perspectiva da sociologia jurídica. Para Gunther Taubner, teórico alemão influenciado por Niklas Luhmann, a metáfora de transplantes legais passa a equivocada ideia de que o material que está sendo transferido vá chegar ao seu destino realizando o mesmo papel e atuando dentro das mesmas condições que anteriormente tinha, agora no novo sistema.

Essa percepção, continua o autor, é equivocada e, ao contrário de uma possível primeira possível intuição do intérprete, o elemento transplantado chegará ao novo sistema não como mais um elemento natural dele, mas sim como um "irritante legal" (TEUBNER, 1998, p.12).

Assim, instituições legais não podem ser facilmente "importadas" de um contexto para o outro. Elas precisam de um processo cuidadoso de implementação e cultivo no novo ambiente. Desta forma, o transplante não pode ser considerado repelido ou integrado. Uma vez recebido um novo instituto, por exemplo, a sociedade irá reagir de alguma maneira e, segundo o autor, essa reação normalmente não é pacífica.

O objeto transplantado, ou seja, o "irritante legal" irá certamente causar inconveniências aos advogados ou juízes tradicionais, por exemplo, exigindo deles novas adaptações em seu trabalho. Mas ele irá, sobretudo, irritar os consensos estabelecidos, os "binding arrangements" dentro daquela sociedade.

Desta maneira, esse "barulho exterior irá criar selvagens perturbações na interface dos discursos dentro desses acordos e irá forçar todos a reconstruírem internamente não apenas suas

\footnotetext{
${ }^{12}$ No original: It is an outside noise which creates wild perturbations in the interplay of discourses within these arrangements and forces them to reconstruct internally not only their own rules but to reconstruct from scratch the alien element itself.

${ }^{13}$ Para todos, citado por Taubner, ver: MARKESINIS, Basil. Learning rom Europe and Learning in Europe. In: Markesinis, B. 9ed). The Gradual Convergence: Foreign
}

próprias regras, mas a reconstruir o próprio elemento estrangeiro" (TEUBNER, 1998, p.12). ${ }^{12}$

Desta forma, os irritantes legais não podem ser domesticados, e jamais poderão ser transformados em algo que possa ser considerado como familiar à cultura que o está recebendo, mesmo em tempos de globalização.

Resta, portanto, a adoção de um transplante legal que será posteriormente e necessariamente desconstruído. É por essa razão que o autor se posiciona crítico ao processo de universalização das normas, dada através da denominada tese da convergência ${ }^{13}$, pautada no funcionalismo e na sua ortodoxa e muitas vezes frustrante busca pela função equivalente das regras em sociedades que são profundamente distintas ${ }^{14}$.

Para Teubner, essas duas premissas, amplamente adotadas no direito comparado atual, conduzem a uma dupla fragmentação da sociedade mundial e levam a novas formas de exclusão a totalidade de diversos segmentos da população, resultado direto dos efeitos da modernização (TEUBNER, 1998, 13).

Desta maneira, é preciso compreender que cada segmento da sociedade mundial enfrenta os problemas jurídicos que são radicalmente distintos, mesmo que possuam a mesma origem, como por exemplo, a globalização. Assim, a melhor solução seria atuar de forma completamente oposta as respostas dadas pela uniformização da legislação e constituir leis ainda mais fragmentadas, mas conectadas com cada realidade local. (TEUBNER, 1998, 13).

O provocante texto de Teubner é considerado por Pierre Legrand um dos cinco artigos mais importante da teoria da comparação nos últimos cinquenta anos e, mesmo que com

Ideas, Foreign Influence, and English Law on the Eve of the 21st Century. Oxford: Clarendon, 1994.

14 Para o funcionalismo, ver: MICHAELS, Ralf. The Functional Method of Comparative Law. In: REIMANN, Mathias; ZIMMERMANN, Reinhard. The Oxford Handbook of Comparative Law. Oxford: Oxford University Press, 2008, p. 339-382. 
alguns importantes pontos que marcam suas diferenças, se aproxima das preocupações fundamentais para a já aventada anteriormente "escola culturalista".

Um de seus mais significativos representantes, Pierre Legrand, ao abordar o tema dos transplantes legais, produziu um dos mais influentes (e áridos) artigos a respeito do assunto, onde defende de forma veemente a impossibilidade da realização dos transplantes jurídicos.

Segundo Legrand, a realização dos transplantes jurídicos é impossível. Mesmo que seja possível identificarmos prováveis convergências jurídicas em diversas sociedades, como instituições ou normativas que aparentemente se aproximem, as profundas estruturas que as norteiam e de onde se baseiam essas leis, notadamente as epistemologias, as culturas e as "mentalidades" permanecem singulares e, portanto, jamais seriam passíveis de serem transplantadas (LEGRAND, 1997).

Assim como Kahn -Freund, Legrand também recupera Montesquieu e sustenta a ideia de que o conteúdo das formulações jurídicas, em razão das particularidades culturais de cada sociedade, mesmo que gramaticalmente idêntico, como por exemplo no caso de uma norma, não será o mesmo, já que é impossível que uma sociedade interprete os sentidos e significados de maneira idêntica à outra, tal a importância que a própria cultura possui em determinar, através da interpretação, o conteúdo desta normativa (LEGRAND, 1997, p.113).

Essa profunda diferença de mentalidade, torna impossível imaginar que as chamadas família da common law e da civil law, por exemplo, possam identificar pontos de universalização de normas para serem aplicadas

\footnotetext{
${ }^{15} \mathrm{O}$ conceito de mentalidade legal para Legrand centra-se na ideia de que há uma maneira particular de pensar sobre a lei, sobre o que é adquirir o conhecimento legal, qual é o papel da lei na sociedade e como ele deve ser realizado. Para mais detalhes da teoria do direito comparado produzida por
}

de forma simultânea em países como Inglaterra e França. Há, aqui, uma profunda diferença epistemológica que impede a aproximação entre as tradições legais que o transplante jurídico pretende realizar (LEGRAND, 1997a, p.45) ${ }^{15}$.

Desta maneira, é necessário sair de uma análise centrada apenas no enunciado e atentar-se à enunciação. Legrand pretende enfatizar que a maneira pela qual o sujeito repete o enunciado está dentro de um enquadramento específico intrinsicamente conectado a uma certa convenção epistemológica. Esta convenção, por sua vez, é resultado de um contexto histórico e de lutas em torno do poder de qual o sentido será dado a um determinado enunciado (FRANKENBERG, 2013, p. 6).

Para o autor canadense, cada linguagem e cada cultura produz seu próprio sistema de sentidos e visões de mundo (GRAZIADEI, 2015, p.467). Desta maneira, eles são balizados por eles. Essas balizas, por sua vez, interferem na maneira com que cada cultura irá constituir a normativa integrada, adaptando-a a sua realidade cultural e, portanto, e forçosamente, alterando-a de maneira profunda a ponto de causar sua desconfiguração. Torna-se, portanto, imperioso assumir a impossibilidade da transposição de uma construção normativa de uma cultura à outra.

No mesmo sentido, mesmo que não abordando claramente uma perspectiva culturalista, Mark Tushnet, ao analisar o pensamento de Hamilton, argumenta pela impossibilidade de transplantes de normas de direito público, especialmente as constitucionais.

As normas de direito público, exatamente pelo fato da incisiva e determinante influência da política em sua formulação, são sobretudo fruto de uma realidade sócio/cultural particular. Desta maneira, torna-se improdutivo realizar aquilo que

Legrand, inclusive a importância do estudo da epistemologia do direito no direito comparado, ver: LEGRAND, Pierre. Pour la relevance des droits étrangers. Paris: IRJS Editions, 2014. p.169-241 
o autor denominou de "recomendações normativas" para o processo de formulação constitucional de uma sociedade distinta da sua. Em resumo, a transposição pura e simples de ideias ou institutos jurídicos, seja por imposição, mas sobretudo por influência, como querem defender alguns teóricos do direito constitucional comparado é, para o autor, "sem sentido" (TUSHNET, 2008, p.1474).

\section{COMO, AFINAL, COMPREENDER OS} TRANSPLANTES JURÍDICOS? TEORIA E CRÍTICA

O debate entre aqueles que pretendem analisar os transplantes jurídicos dando uma maior atenção ao contexto e aqueles que compreendem o processo stricto sensu de transposição de itens jurídicos como suficientemente complexos para reservarem sua abordagem a esta perspectiva nos auxilia a perceber a dificuldade envolvida na análise desse processo.

Esta controvérsia parece se incorporar à tendência clássica do direito comparado em dividir o campo de pesquisa entre aqueles que adoram o modelo do "law in context", e aqueles que dão ênfase aos estudos denominados como "law in books" (EWALD, 2017, p. 23).

De forma paralela, e fruto direto deste debate, surgem novas perspectivas que pretendem, essencialmente, superar as estabelecidas. O desafio de uma transposição que pretende ser a mais útil (e funcional) possível, mas que não abdique do respeito à cultura local, passa a ser, assim, uma das preocupações principais dos autores que abordam o tema.

Neste sentido, posições extremas, apesar de valorosas como pontos de orientação, não nos ajudam a compreender melhor como este fenômeno é realizado. Desta forma, é fundamental procurarmos não cairmos no erro de que todas as práticas jurídicas estão de tal forma embebidas de sua cultura que jamais podem ser transplantadas.

Da mesma maneira, é fundamental estarmos atentos ao risco de considerarmos analisar juridicamente um transplante jurídico, negligenciando a inquestionável influência dos contextos culturais envolvidos (WHITMAN, 2003, p.341-2).

Conscientes dos perigos destes dois tipos de "cantos da sereia", duas reflexões parecem traduzir bem em sua formulação essas preocupações e podem ser pensadas em conjunto com o intuito de produzir um pensamento menos polarizado, mas nem por isso menos rigoroso, em torno do estudo dos transplantes jurídicos.

As propostas de Michele Graziadei e Günter Frankenberg, em que pese serem distintas, não podem ser compreendidas como excludentes. Pelo contrário, suas características e singularidades se apresentam plenamente capazes de serem costuradas para uma melhor compreensão de como pensar os transplantes.

Temos em vista, aqui, que o estudo da transferência de normas ou doutrinas legais nos auxiliam fundamentalmente à uma melhor compreensão da formulação e da mutação do sistema jurídico analisado pelo pesquisador. Para isso, cabe ao jurista formular uma metodologia que esteja preocupada não só com a perspectiva "law in books" do processo.

É compulsório para todo pesquisador do Direito Comparado o investimento numa pesquisa que é interdisciplinar. Isso quer dizer que para uma maior compreensão das origens e sentidos dos itens legais que estão sendo analisados, a análise detida da história, da sociologia, da antropologia, da filosofia e economia são imprescindíveis.

O contexto social envolvido, tanto da sociedade que deu origem ao item quanto do momento e das razões pelas quais a sociedade receptora está realizando essa transferência, será parte da pesquisa, inclusive com grande 
dedicação de tempo e esforço de compreensão analítica do jurista. $\mathrm{O}$ maior desafio do comparatista é aliar em sua pesquisa o rigor científico exigido tanto do Direito, quanto das Ciências que lhe são conexas, num único trabalho.

Para Michele Graziadei, é praticamente impossível compreender o sentido do termo "transplante legais" sem nos questionar quais as mudanças empíricas que os transplantes ocasionam na sociedade onde foram realizados. Neste sentido, a análise que prevalece hoje com relação aos transplantes não pode ser considerada a melhor.

Isso ocorre porque os estudos atuais normalmente se concentram numa macro perspectiva, bem próxima daquela definida por Stein anteriormente e conectada com a ideia do historiador do direito propagada por Alan Watson. Mesmo que as análises consideradas macro tenham sua importância, especialmente no campo dos estudos normativos, uma investigação, por exemplo, sobre o engajamento dos indivíduos a novas normas resultados de transplantes jurídicos, exige uma pesquisa que um amplo panorama não pode oferecer.

Para isso, seria necessário utilizarmos de estudos que vão desde da apreciação criptográfica ${ }^{16}$ oriunda do direito comparado até estudos da psicologia de Lev Vygotsky, passando obrigatoriamente pela linguística. Tudo isto com o intuito de conseguir compreender melhor como os novos mecanismos jurídicos passam a ser adotados pelos indivíduos através de suas ações individuais, sejam elas verbais ou não. Essa compressão, prossegue, é capital para melhor entendermos as dimensões institucionais. (GRAZIADEI, 1999, p. 735).

\footnotetext{
${ }^{16} \mathrm{O}$ termo referência a análise das dimensões silenciosas do direito. Sacco, p. 347-48. No mesmo sentido, ainda segundo Graziadei, ver: Edward Eberle \& Bernhard Grossfeld, Patterns of Order in Comparative Law: Discovering and Decoding Invisible Powers, In: 3Texas Journal of Internacional Law, vol 38, 2003.
}

Assim como ações sociais, os transplantes legais são ações mediadas e é, portanto, fundamental entendermos os instrumentos utilizados para esse fim, como a linguagem e a comunicação. Sem a análise desses instrumentos por parte do comparatista, a percepção dos transplantes pode tomar caminhos totalmente distintos daqueles efetivamente realizados, reduzindo-se a apenas "uma mera reprodução da forma e do conteúdo do original" (GRAZIADEI, 1999, p. 735).

A detida observação do contexto em que esta linguagem está inserida também é fundamental para o estudo dos transplantes jurídicos. Ela tem um papel central na medida em que também nos oferece a oportunidade de identificarmos a importância da ideologia no processo que condução a legitimação das normas transplantadas.

Segundo Graziadei, a ideologia é uma forma de "ação orientada da crença, e responde as necessidades de se construir um consenso ou uma resistência a uma norma transplantada. Ela transforma poder em influência" (GRAZIADEI, 1999, p. 738). ${ }^{17} \mathrm{~A}$ ideologia atuaria assim, como uma "interface entre a prática individual e a ação coletiva".

É exatamente por isso que ela serve para auxiliar o jurista comparatista a identificar, normalmente camufladas em discursos neutros, de cunho universalista e ditos técnicos, camadas de espaços de paternalismos, ou de legitimação de dominação ou de promoção de reformas ou revolução.

Neste entendimento, o estudo da ideologia traz consigo muito mais que uma perspectiva necessariamente conectada com algum valor positivo ou negativo da mesma. Ao contrário, ele

17 Para um estudo sobre a utilização dos transplantes jurídicos, através da harmonização, como instrumento de poder, ver: MERTUS, Julie; BREIER-SHARLOW, Elizabeth. Power, Legal Transplants and Harmonization In: University Of Detroit Mercy Law Review, vol. 81, 2004. pp. $477-487$ 
é essencial a uma melhor percepção do papel do prestígio nos transplantes legais (GRAZIADEI, 1999, p. 739).

Essa pode ser considerada uma das vantagens da microanálise (ou micro perspectiva) de um transplante legal. Ele possibilita ao pesquisador realizar um recorte de pesquisa que, além mais rigoroso, considera como tanto análise positiva quanto a contextual como partes importantes do seu trabalho para identificar suas conclusões finais.

A microanálise possibilita que o pesquisador, ao dedicar-se a temas mais restritos e delimitados, possa estabelecer uma pesquisa caracterizada pela profundidade no lugar da amplitude, ao mesmo tempo que interdisciplinaridade passa a ser uma ferramenta indispensável para a compreensão do fenômeno.

A contribuição de Günther Frankenberg para os estudos dos transplantes legais, por sua vez, surge de sua preocupação em estudar o constitucionalismo global e suas fissuras. Essa preocupação não impede que suas conclusões possam ser absorvidas pelo campo das pesquisas do direito privado, onde constantemente observamos o processo de transplantes jurídicos.

Com uma grande influência da teoria crítica do Direito, Frankenberg traz importantes reflexões sobre quais são as preocupações que devem fazer necessariamente parte do trabalho do pesquisador envolvido no tema.

Desta maneira, seu objetivo principal é enquadrar a perspectiva crítica do estudo do direito comparado dentro dos estudos das correntes majoritárias do campo. Os transplantes jurídicos seriam, assim e sobretudo, mais um dos instrumentos adotados para que este alvo fosse alcançado (FRANKENBERG, 2013, p. 2).

\footnotetext{
${ }^{18}$ Um importante exemplo que demonstra um esforço coordenado no sentido contrário ao empreendido no processo de globalização jurídica atrelada a dominação Anglo-eurocêntrica é o reconhecimento do Guarani como língua não só oficial, mas utilizada na prática diária do Tribunal Permanente do Mercosul. Para detalhes, ver:
}

Seu trabalho nos auxilia a compreender a dimensão política dos transplantes e sua utilização como instrumento de, sob o pretexto de uma eventual globalização jurídica atravessada pelo mundo, aplicação de um processo de dominação "Anglo-Eurocêntrica"18.

Ao nos alertar para a dimensão política dos transplantes, Frankenberg dá a dimensão contextual um importante e estratégico espaço no estudo dos transplantes. Este movimento é muito importante. A dimensão política pode até ser considerada menos imperativa quando focamos nossos estudos em países da Europa do Oeste ou da América do Norte. Por outro lado, qualquer país que tenha passado pelo processo de colonização, como é o caso do Brasil, não pode prescindir de tê-la como parte de suas preocupações, por razões historicamente evidentes.

Com o objetivo de se afastar desse processo convergente, universalista e acrítico aplicado aos estudos dos transplantes legais, Frankenberg propõe aquilo que ficou designado de teoria Ikea ${ }^{19}$ das transferências constitucionais. Esta teoria está centrada na análise das transferências de normas constitucionais de um ordenamento jurídico a outro.

Segundo o autor, a metáfora Ikea tem dois objetivos principais. O primeiro deles é clarificar a perspectiva política, que todo processo de transferência de itens legais para a realização do "constitutional-making" possui. Para o autor, é fundamental desconstruir o mito do idealismo e do naturalismo que prevalece em torno deste tipo de estudo, sobrepondo uma análise mais crítica deste processo.

Ao mesmo tempo ele pretende realçar como os autores são inspirados e influenciados no

VASCONCELOS, Raphael Carvalho De. El Guaraní y el Mercosur: una cuestión de derechos humanos. Rev. secr. Trib. perm. revis., v. 3, p. 11-14, 2015.

${ }^{19}$ Parafraseando a conhecida loja de matérias domésticos originária da Suécia. 
processo de "pedir emprestado" um item jurídico e, por sua vez, alterar elementos de materiais constitucionais importados (FRANKENBERG, 2013, p. 4).

O segundo objetivo, considerado por ele como mais complexo e custoso, é abordar o conceito, o processo e as dificuldades de migração de transferência dos formatos legais. Aqui, Frankenberg, assim como Graziadei, assume claramente sua posição em prol da possibilidade dos transplantes legais e se afasta da posição de Pierre Legrand.

Isso não significa, contudo, que ele entenda os transplantes como um processo "agnóstico ou neutro" e centra seus esforços não na possibilidade positiva ou negativa o da realização dos transplantes legais, mas nos mecanismos e condições que facilitam ou impedem a sua realização.

Os transplantes são, portanto, fatos da realidade jurídica, que trazem consigo importantes premissas e consequências que não podem deixar de serem objetos de exame do comparatista. Desta maneira, ele inicia seu processo de "decupagem ", ou seja, de detalhamento, deste procedimento alimentandose do trabalho de Edward Said sobre a migração de teorias e ideias.

O objetivo é identificar quais seriam as fases do transplante legal para, com isso, realizarmos de uma maneira mais rigorosa e crítica sua análise. Essas fases, por sua vez, não devem ser entendidas como uma sequência rigorosa e com apenas uma via de passagem, mas, ao contrário, como uma diversidade de caminhos que podem ser seguidos no procedimento de importar ou exportar matérias jurídicos (FRANKENBERG, 2013, p. 9).

Do ponto de vista metodológico, continua o autor, não é possível identificar de forma adequada qual o caminho que é adotado nesse processo de transferência. Por outro lado, o que pode ser identificado é um primeiro processo de descontextualização dos materiais que são transplantados. Esses materiais, ao atravessar as "fronteiras culturais" que estão inseridos perdem as características epistemológicas que os marcam.

Neste sentido, eles acabam passando por alguns processos. $\mathrm{O}$ primeiro deles é a reificação, ou seja, há um processo de objetificação das ideias jurídicas. Assim, um amplo conjunto de termos com sentidos considerados vivos, como por exemplo, diversas doutrinas ou termos como "norma" ou "instituição", passam por um processo de retirada de sentidos, de esfolamento que suprime deles seu contexto histórico, social e cultural. Desta maneira, eles deixam de ser o resultado de um fenômeno cultural específico e passam, pelo menos em sua superfície a se tornarem verdadeiras "commodities" (FRANKENBERG, 2013, p. 11).

Num segundo momento, a formalização reduz esses materiais a meros textos, destituídos de qualquer possibilidade de debates interpretativos ou convenções epistêmicas capazes de dar sentido aos mesmos. Desta forma, instituições são reduzidas a conteúdos ou proposições meramente descritivas sobre algum tipo de organização ou arranjo institucional (FRANKENBERG, 2013, p. 11).

Por fim, há o processo que consideramos o mais perigoso dentro dos transplantes legais. A idealização desta nova “commodities”, ou seja, há uma transformação da aparência dessas normas, doutrinas ou instituições. Isso significa que elas são tratadas, necessariamente, como objetos com um valor certamente positivo que irão produzir o resultado esperado pelo receptor.

Assim, instituições são apresentadas como altamente produtivas e funcionais, doutrinas estrangeiras como a melhor resposta crítica a uma questão jurídica local e decisões de juízos específicos como as melhores interpretações da lei, por exemplo. Tudo isso justificado, habitualmente, por ideologias que sustentam os 
discursos de autoridade advindos do prestígio do sujeito "doador" do transplante.

O resultado da idealização não poderia ser diferente. Há, com isso, além do afastamento do objeto idealizado de sua realidade efetiva, a implementação de uma ideologia prédeterminada que atua como uma efetiva camuflagem dos sentidos contextualizados do item transplantado, oferecendo ao receptor somente "a história oficial" deste produto (FRANKENBERG, 2013, p. 11).

Assim como no processo de transferência de itens ligados ao direito constitucional, o que Frankenberg avalia, de forma correta, é a constituição de uma seleção de objetos transferíveis que, descontextualizados, passam a fazer parte de um repertório global (uma verdadeira Ikea legal) como se fossem as melhores respostas jurídicas para todos os problemas enfrentados pelas sociedades contemporâneas.

Esses produtos podem ser usados não somente pelos consultores estrangeiros evidenciados por Tushnet, mas pela elite jurídica que, sem a realização de uma análise crítica, incorpora o processo de idealização de uma maneira ainda mais perigosa, por estar, por sua própria condição, mais legitimada a falar do seu direito que o analista estrangeiro.

A questão se agrava ainda mais exatamente no momento em que, assim como diversos produtos comercializados no mundo globalizado, o comprador "receptor" não conhece as origens daquele produto (o item jurídico transferido) e, portanto, está desinformado de pré-requisitos contextuais que são fundamentais para orientar sua escolha. (FRANKENBERG, 2013, p. 13).

Sem essa atenção necessária, é perfeitamente possível que haja a escolha por parte do país receptor de um item jurídico

${ }^{20}$ Para um exemplo deste processo, ver: GARGARELLA, Roberto. Constitutional grafts and social rights in Latin America. In: FRANKENBERG, Günther (ed). Order From estrangeiro idealizado, digamos, do direito penal ou civil, sem sequer ter a fundamental informação de que sua aplicação só foi bem-sucedida num determinado país, pois ele possuía uma sociedade, por exemplo, mais igualitária tendo, por outro lado, fracassado em países onde há uma desigualdade econômica profunda.

Neste sentido, jamais poderemos dizer que há itens com aplicabilidade universal, na medida em que uma análise contextual e sem a idealização característica de muitos transplantes legais é parte fundamental do processo de transferência jurídica entre Estados.

Um quarto passo construtivo do transplante também é analisado por Frankenberg: a "recontextualização". A "recontextualização" pressupõe, num primeiro momento, a retirada do "embrulho" em volta do item transferido. Isso significa que o item precisa passar por uma seria de movimentos que o adaptam, introduzem e modificam o objeto no seu processo de reinterpretação e redesignação. (FRANKENBERG, 2013, p. 19).

Neste sentido, ainda na esteira de Said, Frankenberg acredita ser necessário a inserção deste novo item dentro do quadro jurídico para onde ele foi transplantado, adotando aqui uma recontextualização e uma consequente reconfiguração de seus sentidos para serem reconhecidos dentro da nova comunidade epistêmica, notadamente as cortes ou a academia. (FRANKENBERG, 2013, p. 19).

Há, portanto, uma verdadeira e obrigatória transformação, que começa da ruptura com a idealização, através da adoção de um novo lugar deste objeto transplantado dentro do seu novo sistema jurídico com uma consequente alteração de sua utilização. ${ }^{20}$

Este processo corre dois sérios riscos. $\mathrm{O}$ primeiro deles são as "reações imunológicas" do

Transfer: Comparative constitutional Desing and Legal Culture. Cheltenham: Edward Elgar Publishing, 2013. Pp.322-349 
sistema receptor. Ou seja, a abstração do item transplantado pode não ser suficientemente adaptável e pode sofrer uma série de resistências políticas e sociais, além, é claro, o risco de o item idealizado não fazer nenhum sentido dentro desse novo sistema jurídico.

Outro risco, este considerado mais comum, é a realização de um "ajuste deficiente". Isto pode acontecer quando o item não pode ser nem adaptado, nem utilizado por ausência de importantes informações a respeito dele, como por exemplo, com a importação de modelos de instituições ou até mesmo de doutrinas fortemente contextualizadas, como visto de forma recorrente no Brasil.

A falha deste procedimento pode levar com que o receptor volte ao "mercado" na busca de novos "produtos" para substituir o anterior ou exigir dele que uma nova opção seja constituída dentro do próprio sistema. É importante destacar, contudo, que a aparente similaridade dos produtos passíveis de transplante não irá resistir a necessária contextualização que irá aplicar no interior destes itens novos sentidos e convenções (FRANKENBERG, 2013, p. 21).

Neste sentido, cabe ao comparatista superar a simplificação de muitos estudos que giram em torno dos transplantes jurídicos ou que se fundamentam nele e começar a se preocupar em analisar de forma atenta os importantes momentos de descontextualização, ressignificação, idealização e recontextualização que todo transplante jurídico parece necessariamente sofrer no país.

Uma análise rigorosa em cada fase desse percurso, adotando a perspectiva da micro comparação, e com uma forte característica interdisciplinar, é essencial para que o trabalho do comparatista possa ser caracterizado pela crítica, destrinchando e revelando camadas que vão, é bem verdade, para além do direito, mas estão, sobretudo, intrinsicamente conectadas a ele e por isso mesmo não podem deixar de serem avaliadas pelo jurista.

\section{CONCLUSÃO}

O estudo do direito comparado, especialmente dos transplantes legais, apesar de relegado a um grupo restrito de pesquisadores, possui importância fundamental na compreensão crítica de qualquer ordenamento jurídico.

Este trabalho, por sua vez, foi objeto de um amplo e histórico debate no campo do direito comparado envolvendo em dois extremos um grupo preocupado com a perspectiva cultural da transferência de itens jurídicos e outro que centra seus esforços numa análise que pode ser denominada de pragmática, ou positiva.

Com o intuito de superar o debate estabelecido, diversas novas abordagens propuseram a fornecer ao jurista sua posição a respeito do tema, sem, contudo, deixar de salientar sua importância. Entre elas, duas se destacam.

A atuação de Michele Graziadei, ao valorizar a micro perspectiva para o estudo dos transplantes jurídicos possibilita ao pesquisador uma abordagem mais rigorosa, por ter um objeto mais delimitado e, sobretudo, interdisciplinar, cumprindo um requisito obrigatório para todo e qualquer estudo de Direito Comparado.

A este tratamento podemos somar a contribuição de Günther Frankenberg, que através de sua preocupação com a realização de um direito comparado crítico oferece ao leitor um tratamento do estudo dos transplantes jurídico não só metodologicamente organizado, bem como com uma apreciação crítica, destacando a importância do estudo da (s) política (s) envolvidas nos transplantes jurídicos.

Acreditamos que as alternativas teóricas oferecidas por esses autores, se bem alinhadas, podem oferecer ao pesquisador, especialmente ao brasileiro, uma saudável linha de partida para o 
trabalho minucioso e aprofundado do estudo deste campo.

Os transplantes jurídicos, reconhecido campo do direito comparado, por mais que dissemine de forma basilar e imperiosa seus resultados em grande parte das outras áreas do estudo do direito, ainda é, surpreendentemente, pouco interpelado por eles. É chegada a hora de suprirmos essa lacuna de forma rigorosa e crítica.

\section{REFERÊNCIAS}

CAIRNS, John W. Watson, Walton, And The History Of Legal Transplants. In: Georgia Journal of International and Comparative Law, vol. 41, pp. 637-686, 2013.

CHAMPEIL-DESPLATS, Véronique. Méthodologies du Droit et des Sciences du Droit. Paris: Dalloz, 2014.

DUVE, Thomas. Legal traditions: A dialogue between comparative law and comparative legal history. Comparative Legal History, vol. 6, n. 1, pp. 15-33, 2018.

EWALD, William. Comparative Jurisprudence (II): The Logic of Legal Transplants. The American Journal of Comparative Law, vol. 43, pp. 489-510, 1995.

. Rats in Retrospect. In: BESSON, Samantha; URSCHELER, Lukas; JUBÉ, Samuel. Comparing Comparative Law. Geneva/Zurich: Schulthess Éditions Romandes, 2017.

FRANKENBERG, Günther (ed). Order From Transfer: Comparative constitutional Desing and Legal Culture. Cheltenham: Edward Elgar Publishing, 2013.

. Constitutions As Commodities Notes On A Theory of Transfer. Comparative Law Review, vol.4, n. 1, pp. 1-30, 2013.

Constitutional transfer: The IKEA theory revisited. International journal of Constitutional Law, vol. 8, n. 3, pp. 563-579, 2010.

GRAZIADEI, Michele. Comparative Law as the Study of Transplants and Receptions. In: REIMANN, Mathias; ZIMMERMANN, Reinhard. The Oxford Handbook of Comparative Law. Oxford: Oxford University Press, 2015.

1999.

. Legal Transplants and the Frontiers of Legal Knowledge. Theoretical Inquiries in Law, v.10,

HALPÉRIN, Jean Louis. Profils des Mondialisations du droit. Paris: Dallloz, 2009.

HUXLEY, Andrew. Jeremy Bentham on Legal Transplants. Journal Of Comparative law, vol. 2, n. 2, pp. 187-188, 2007. 
KAHN-FREUND, Otto. On Uses and Misuses of Comparative Law. Modern Law review, vol. 37, 1974.

LEGRAND, Pierre. The Impossibility of Legal Transplants. Maastricht Journal of European and Comparative Law, vol. 4, n. 2, pp. 111-124, 1997.

Against a European Civil Code. Modern Law Review, vol. 60, n. 1, pp. 44-63, 1997a.

REIMANN, Mathias (ed). The Reception of Continental Ideas in the Common Law World 1820-1920. Berlin: Duncker \& Humblot, 1993.

ÖRÜCÜ, Erin. Law as Transposition. International \& Comparative Law Quarterly, vol. 51, pp. 205223, 2002.

SACCO, Rodolfo. Les buts et les méthodes de la comparaison du droit. In: Rapports nationaux italiens au IX Congrès international de droit comparé, Téhéran, 1974.

Legal Formants: A Dynamic Approach to Comparative Law (Installment I of II). American Journal of Comparative Law, vol. 39, n. 1, pp. 1-34, 1991.

Legal Formants: A Dynamic Approach to Comparative Law (Installment II of II). American Journal of Comparative Law, vol. 39, n. 3, pp. 343-401, 1991 a.

STEIN, Eric. Uses, Misuses-and Nonuses of Comparative Law. NW. U. L. Review, n. 72, pp. 198, 1997.

TEUBNER, Gunther. Legal Irritans: Good Faith in British Law or How Unifying Law Ends Up in New Divergences. Modern Law Review, vol. 61, pp. 11-32, 1998.

TUSHNET, Mark. Some Skepticism about Normative Constitutional Advice. William \& Mary Law Review, vol. 49, n. 4, pp. 1473-95, 2008.

WALTON, F.P. The Historical School of Jurisprudence and Transplantations of Law. J.COMP. LEGIS. \& International Law, vol. 9, n. 1, 1927.

WATSON, Alan. Legal Transplants: an Approach to Comparative Law. 2 ed $^{\circ}$. Georgia: University of Georgia Press, 1974. . Legal Transplants and Law Reform. The Law Quarterly Review, n. 92, 79-84, 1976.

WHITMAN, James W. Hitler's American Model: The United States and the Making of Nazi Race Law. Princeton: Princeton University Press, 2017. 
The Neo-Romantic Turn. In: P. Legrand and R. Munday (eds.), Comparative Legal Studies: Traditions and Transitions. Cambridge University Press, Cambridge, 2003.

WISE, Edward M. The Transplant of Legal Patterns. The American Journal of Comparative Law, vol. 38, pp. 1-22, 1990.

Recebido em: 05/06/2018 Aceito em: 06/09/2018 
